\title{
Strategi Pengembangan Model Bisnis Klaster Industri Tomat Krispi Daumato Berdasarkan Analisis SWOT dan BMC
}

\author{
Aang Fajar Passa Putra ${ }^{1^{*}}$, Fenda Ramadhani ${ }^{2}$, \\ 12Teknik Industri,Universitas Merdeka Malang \\ *Korespondensi Penulis, E-mail: aang.fajar@unmer.ac.id
}

\begin{abstract}
Abstrak
Klaster Industri Tomat Krispi Daumato merupakan unit usaha kecil hasil pemberdayaan CE Djarum Beasiswa Plus yang dibentuk oleh tim Beswan Djarum dari berbagai Perguruan Tinggi di Kota Malang. Sejak dibentuk hingga dilaksanakannya penelitian, industri ini belum mampu menjalankan model bisnis dengan efektif, sehingga diperlukan strategi-strategi pengembangan untuk membantu mengembangkan model bisnisnya. Tujuan penelitian ini yaitu (1) Menganalisis klaster Industri Tomat Krispi Daumato dengan Diamond Porter Model; (2) Menganalisis pemetaan model bisnis 9 elemen Business Model Canvas (BMC) dengan analisis SWOT (Strenght, Weakness, Opportunity dan Threats); (3) Merumuskan strategi pengembangan model bisnis klaster industri Tomat Krispi Daumato menggunakan matrik SWOT. Metode analisis dalam penelitian ini menggunakan kombinasi pendekatan Diamond Porter Model, analisis BMC dan matriks SWOT dalam merumuskan strategi pengembangan bisnis Klaster Industri Tomat Krispi Daumato. Hasil penelitian menunjukkan perlu adanya pengembangan pada model bisnis Klaster Industri Tomat Krispi Daumato. Adapun strategi pengembangan model bisnisnya adalah (1) Membentuk sebuah koperasi; (2) Mempertahankan kualitas bahan baku tomat; (3) Mengembangkan potensi usaha dengan menjalin jaringan dengan mitra-mitra strategis; (4) Mempertahankan hubungan dengan konsumen dengan membuka peluang menjadi pemasok (supplier); (5) Meningkatkan penjualan produk untuk mengantisipasi adanya bahan dengan harga yang fluktuatif.
\end{abstract}

Kata Kunci : Strategi Pengembangan, Klaster Industri, SWOT, BMC, Tomat Krispi Daumato

\section{Pendahuluan}

Tomat merupakan salah satu jenis sayuran yang umum dimanfaatkan menjadi produk olahan oleh masyarakat di Desa Tegalweru, Kecamatan Dau, Kabupaten Malang. Dalam satu tahun, petani tomat di Desa Tegalweru bisa melakukan panen mencapai $1-3$ ton setiap panen dengan 2 hingga 3 kali panen setiap tahunnya. Salah satu bentuk pengolahan tomat menjadi sebuah camilan yang mampu menambah nilai jual yaitu olahan tomat krispi dengan merek Daumato.

Daumato merupakan produk hasil pemberdayaan masyarakat dari program Community Empowerment (CE) Djarum Beasiswa Plus yang merupakan bagian dari Program Djarum Foundation. Pemberdayaan tersebut meliputi kelompok masyarakat yang terdiri dari Kelompok Tani, Anggota Karang Taruna dan Ibu-ibu PKK, berjalan selama kurang lebih satu tahun dan telah memberikan hasil menguntungkan. Daumato telah memiliki ijin produksi rumah tangga dan mampu memproduksi hingga 1.012 kemasan dengan menghasilkan pendapatan kotor sebesar Rp 8.500.000,- (Februari 2019).

Beberapa faktor eksternal dan internal dalam produk Daumato terbentuk menjadi sebuah Klaster Industri. Klaster Industri adalah upaya pengelompokan industri inti yang saling berhubungan, baik dengan industri pendukung, industri terkait, jasa penunjang, infrastuktur ekonomi dan lembaga terkait [6]. Beberapa hasil penelitian terkait klaster industri dan strategi bisnisnya antara lain : Petir Papilo, Tajuddin Bantacut (2016) [5] Nyanyu Rizkita, Rizal Syarief dan Ono Suparno (2018) [7] dan Budi Susanto (2007) [8]. Susanto (2007) membahas evaluasi klaster industri. Papilo dan Bantacut (2016) menggunakan klaster industri dalam menerapkan strategi bisnis dimana penelitian ini 
membahas tentang peningkatan daya saing klaster industri. Penelitian Nyanyu Rizkita, Rizal Syarief dan Ono Suparno (2018) membahas strategi pengembangan perbaikan terhadap setiap elemen pada model bisnis klaster industri untuk produk Olahan Susu [7].

Pascapemberdayaan masyarakat oleh Tim Beswan Djarum di Desa Tegalweru Dau Malang, dilakukan pendampingan terhadap jalannya klaster industri tomat krispi Daumato yang sudah terbentuk. Berdasarkan hasil evaluasi ternyata terdapat beberapa permasalahan yang dapat diidentifikasi berdasarkan pada faktor eksternal dan internal produk Daumato. Untuk faktor ekstenal, merek (brand) produk Daumato masih belum banyak dikenal dan rendahnya tingkat permintaan konsumen. Sedangkan untuk faktor internal, ditemukan kurangnya partisipasi dan inisiatif masyarakat dalam mengelola sistem pemesanan, kualitas, harga dan penjualan.

Salah satu upaya untuk mengatasi permasalahan-permasalahan tersebut dilakukan pengembangan klaster industri yang mencakup pengembangan Model Bisnis Klaster Industri menggunakan metode SWOT sebagai alat formulasi strategi dan identifikasi berbagai faktor secara sistematis untuk merumuskan strategi perusahaan [2]. Hasil penelitian Uyu Lumsari (2007) menggunakan metode SWOT dalam strategi pengembangan dimana penelitian ini membahas tentang diperlukan adanya suatu konsep analisis yang mendalam akan faktor internal dan eksternal yang dimiliki oleh Klaster Industri [3].

Produk Daumato merupakan unit usaha kecil yang baru saja terbentuk, maka perlu dianalisis menggunakan Diamond Porter Model untuk mengetahui kemampuan suatu industri untuk memperoleh keunggulan kompetitif yang terdiri dari enam faktor yaitu Factor Condition, Related and Supporting Industries, Government, Demand Conditions, Firm Strategy, Structure and Rivalry dan Chance [1].

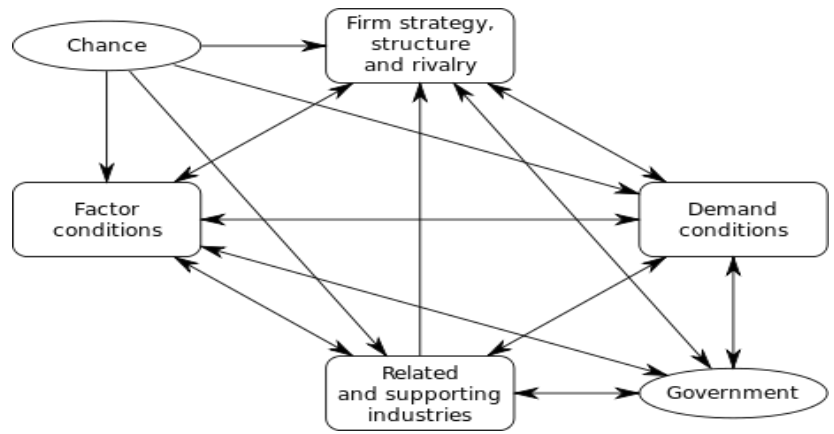

Gambar 1.1. Porter's Diamond Model

Selanjutnya untuk menyederhanakan konsep model bisnisnya agar dapat digunakan oleh organisasi atau perusahaan untuk membuat dan memahami strategi bisnis yang didesain, dikerucutkan menjadi satu strategi Business Model Canvas (BMC). Penelitian Vera Sylvia (2017) menggunakan metode BMC dalam merancang model bisnis canvas sebagai bentuk strategi pengembangan bisnis [9]. BMC terdiri dari sembilan elemen yaitu Customer Segments, Value Proportion, Channels, Customer Relationship, Revenue Streams, Key Resources, Key Activities, Key Partnerships dan Cost Structure [4].

\begin{tabular}{|c|c|c|c|c|}
\hline \multirow[t]{2}{*}{ KEY PARTNERS } & KEY ACTIVTIES & \multirow{2}{*}{ VALUE PROPOSITION } & $\begin{array}{l}\text { CUSTOMER } \\
\text { RELATIONSHIPS }\end{array}$ & \multirow[t]{2}{*}{ CUSTOMER SEGMENTS } \\
\hline & KEY RESOURCES & & CHANNELS & \\
\hline COST STRUCTURE & & & & \\
\hline
\end{tabular}




\section{Gambar 1.2. Template BMC}

Setelah mengetahui elemen-elemen bisnis penting tersebut, selanjutnya dianalisis dengan menggunakan SWOT. Berdasarkan matriks SWOT terhadap 9 (sembilan) elemen bisnis BMC maka dapat dirumuskan strategi pengembangan model bisnis klaster industri produk Daumato di Desa Tegalweru Kecamatan Dau Kabupaten Malang.

\section{Metode}

Tahap pengumpulan dan pengolahan data yang dilakukan:

1. Tahap Identifikasi Berdasarkan SWOT

a. Melakukan penyusunan dan penyebaran kuesioner kepada konsumen dan stakeholders yang sudah ditentukan.

b. Melakukan wawancara terhadap stakeholders untuk menyusun faktor-faktor SWOT

c. Menghitung pembobotan hasil kuesioner terhadap konsumen dan stakeholders (IFAS \& EFAS Matrix) dan menentukan hasil kuadran strategi SWOT.

2. Tahap Identifikasi Elemen Diamond Porter Model berdasarkan hasil SWOT.

3. Tahap Analisis Business Model Canvas (BMC)

a. Melakukan pemetaan 9 elemen bisnis BMC.

b. Menganalisis 9 elemen bisnis BMC dengan SWOT

4. Tahap Penentuan Strategi Pengembangan

a. Analisis Matrik Interaksi SWOT

b. Pembahasan strategi pengembangan Klaster Industri Daumato.

5. Kesimpulan dan Saran

\section{Hasil dan Pembahasan Identifikasi SWOT}

Faktor-faktor SWOT yang diperoleh dari data hasil kuesioner terhadap stakeholders akan diolah untuk metode Diamond Porter Model dan Business Model Canvas. Dalam pengumpulan data untuk SWOT hanya menggunakan data hasil kuesioner stakeholders yaitu Tim Beswan, Ibu-ibu PKK dan Karang Taruna yang mengetahui strategi model bisnis Klaster Industri Tomat Krispi Daumato. Untuk data kuesioner terhadap konsumen hanya menjadi gambaran dari sisi eksternal konsumen produk Daumato. 


\begin{tabular}{|c|c|c|}
\hline No. & Strength (Kekuatan, S) & Ket. \\
\hline 1. & Daumato telah memiliki ijin produksi & S1 \\
\hline 2. & Tempat produksi yang memadai & S2 \\
\hline 3. & Dukungan masyarakat dan dukungan dana Djarum Foundation & S3 \\
\hline 4. & Bahan baku tersedia & S4 \\
\hline 5. & Memiliki laman khusus dan media sosial (instagram) untuk promosi & S5 \\
\hline No. & Weakness (Kelemahan, W) & Ket. \\
\hline 1. & Kurangnya inisiatif masyarakat dalam mengelola industri & W1 \\
\hline 2. & Kurangnya pengalaman dalam menjalankan bisnis & W2 \\
\hline 3. & Kurangnya pengetahuan bisnis para pengelola usaha & W3 \\
\hline 4. & Konsistensi anggota kurang maksimal & W4 \\
\hline 5. & Belum menemukan vendor kemasan skala besar & W5 \\
\hline No. & Opportunity (Peluang, 0 ) & Ket. \\
\hline 1. & Potensi sumberdaya yang mendukung kegiatan usaha & $\mathrm{O} 1$ \\
\hline 2. & Perluasan distribusi melalui e-commerce & $\mathrm{O} 2$ \\
\hline 3. & Pelaku pasar terbuka lebar & O3 \\
\hline 4. & Pelopor inovasi produk tomat krispi & $\mathrm{O} 4$ \\
\hline No. & Threats (Ancaman, T) & Ket. \\
\hline 1. & Harga Daumato lebih mahal dibanding pesaing & T1 \\
\hline 2. & Pesaing yang terus mengeluarkan produk sejenis (keripik) & T2 \\
\hline 3. & Harga bahan baku tomat yang fluktuatif & T3 \\
\hline 4. & $\begin{array}{l}\text { Cuaca yang tidak mendukung memengaruhi pertumbuhan bahan baku } \\
\text { tomat }\end{array}$ & T4 \\
\hline 5. & Hama mengganggu pertumbuhan bahan baku tomat & T5 \\
\hline
\end{tabular}

\section{Pembobotan Matrik IFAS (Internal Factor Analysis Strategy) dan EFAS (External Factor Analysis Strategy)}

Dari hasil faktor-faktor SWOT, maka dianalisis matriks IFAS dan EFAS untuk menghitung bobot faktor internal dan eksternal dan ditentukan dalam diagram analisa SWOT agar mengetahui letak kuadran strategi Klaster Industri Tomat Krispi Daumato. Untuk skor setiap variabel didapatkan dari hasil kuesioner terhadap stakeholders Klaster Industri Tomat Krispi Daumato. Sedangkan hasil pembobotan didapatkan dari hasil FGD (Forum Group Discussion) dengan stakeholders Daumato dengan memberikan ranking tingkat kepentingan setiap variabel.

Tabel 3.2. Pembobotan Matrik IFAS

\begin{tabular}{|c|c|c|c|c|c|c|c|c|c|c|c|}
\hline \multirow{2}{*}{ Responden } & \multicolumn{5}{|c|}{ Variabel Strength } & \multicolumn{5}{|c|}{ Nilai $\times$ Bobot } & \multirow{2}{*}{ Total } \\
\hline & S1 & $\mathrm{S} 2$ & S3 & S4 & S5 & 0,2 & 0,2 & 0,4 & 0,1 & 0,1 & \\
\hline 1 & 4 & 4 & 4 & 5 & 4 & 0,8 & 0,8 & 0,8 & 1 & 0,8 & 4,2 \\
\hline 2 & 5 & 4 & 5 & 5 & 5 & 1 & 0,8 & 1 & 1 & 1 & 4,8 \\
\hline 3 & 5 & 4 & 4 & 4 & 5 & 1 & 0,8 & 0,8 & 0,8 & 1 & 4,4 \\
\hline 4 & 5 & 5 & 4 & 4 & 4 & 1 & 1 & 0,8 & 0,8 & 0,8 & 4,4 \\
\hline 5 & 5 & 4 & 4 & 4 & 5 & 1 & 0,8 & 0,8 & 0,8 & 1 & 4,4 \\
\hline 6 & 5 & 5 & 4 & 5 & 5 & 1 & 1 & 0,8 & 1 & 1 & 4,8 \\
\hline 7 & 5 & 4 & 4 & 4 & 4 & 1 & 0,8 & 0,8 & 0,8 & 0,8 & 4,2 \\
\hline 8 & 5 & 3 & 4 & 4 & 5 & 1 & 0,6 & 0,8 & 0,8 & 1 & 4,2 \\
\hline 9 & 5 & 4 & 4 & 5 & 5 & 1 & 0,8 & 0,8 & 1 & 1 & 4,6 \\
\hline 10 & 5 & 4 & 5 & 5 & 4 & 1 & 0,8 & 1 & 1 & 0,8 & 4,6 \\
\hline & & & Total & Str & & & & & & & 44,6 \\
\hline
\end{tabular}

\begin{tabular}{|c|c|c|c|c|c|c|c|c|c|c|c|}
\hline \multirow{2}{*}{ Responden } & \multicolumn{5}{|c|}{ Variabel Weakness } & \multicolumn{5}{|c|}{ Nilai $\times$ Bobot } & \multirow{2}{*}{ Total } \\
\hline & W1 & $\mathrm{W} 2$ & W3 & W4 & W5 & 0,5 & 0,1 & 0,1 & 0,2 & 0,1 & \\
\hline 1 & 4 & 3 & 3 & 3 & 4 & 0,8 & 0,6 & 0,6 & 0,6 & 0,8 & 3,4 \\
\hline 2 & 5 & 5 & 4 & 5 & 5 & 1 & 1 & 0,8 & 1 & 1 & 4,8 \\
\hline 3 & 3 & 4 & 3 & 4 & 4 & 0,6 & 0,8 & 0,6 & 0.8 & 0,8 & 3.6 \\
\hline 4 & 3 & 3 & 4 & 5 & 3 & 0,6 & 0,6 & 0,8 & 1 & 0,6 & 3,6 \\
\hline 5 & 4 & 4 & 3 & 4 & 4 & 0,8 & 0,8 & 0,6 & 0,8 & 0,8 & 3,8 \\
\hline 6 & 3 & 3 & 3 & 3 & 2 & 0.6 & 0,6 & 0,6 & 0,6 & 0,4 & 2.8 \\
\hline 7 & 4 & 4 & 4 & 4 & 5 & 0,8 & 0,8 & 0,8 & 0,8 & 1 & 4,2 \\
\hline 8 & 4 & 4 & 4 & 4 & 5 & 0,8 & 0,8 & 0,8 & 0,8 & 1 & 4,2 \\
\hline 9 & 3 & 3 & 2 & 3 & 3 & 0,6 & 0,6 & 0,4 & 0,6 & 0,6 & 2,8 \\
\hline 10 & 4 & 4 & 4 & 4 & 4 & 0,8 & 0,8 & 0,8 & 0,8 & 0,8 & 4 \\
\hline \multicolumn{11}{|c|}{ Total Weakness } & 37,2 \\
\hline & & isih. & Streng & th $\mathrm{da}$ & $\mathrm{n} W e a$ & kness & & & & & 7,4 \\
\hline
\end{tabular}

\section{Tabel 3.3. Pembobotan Matrik EFAS}

\begin{tabular}{|c|c|c|c|c|c|c|c|c|c|}
\hline \multirow{2}{*}{ Responden } & \multicolumn{4}{|c|}{ Variabel Opportunity } & \multicolumn{4}{c|}{ Nilai $\times$ Bobot } & \multirow{2}{*}{ Total } \\
\cline { 2 - 9 } & $\mathrm{O} 1$ & $\mathrm{O} 2$ & $\mathrm{O} 3$ & $\mathrm{O} 4$ & 0,5 & 0,1 & 0,3 & 0,1 & \\
\hline 1 & 4 & 5 & 4 & 4 & 0,8 & 1 & 0,8 & 0,8 & 3,4 \\
\hline 2 & 5 & 5 & 5 & 5 & 1 & 1 & 1 & 1 & 4 \\
\hline 3 & 4 & 5 & 4 & 4 & 0,8 & 1 & 0,8 & 0,8 & 3,4 \\
\hline 4 & 3 & 4 & 4 & 4 & 0,6 & 0,8 & 0,8 & 0,8 & 3 \\
\hline 5 & 4 & 5 & 4 & 4 & 0,8 & 1 & 0,8 & 0,8 & 3,4 \\
\hline 6 & 4 & 3 & 4 & 4 & 0,8 & 0,6 & 0,8 & 0,8 & 3 \\
\hline
\end{tabular}

\begin{tabular}{|c|c|c|c|c|c|c|c|c|c|c|c|}
\hline \multirow{2}{*}{ Responden } & \multicolumn{4}{|c|}{ Variabel Threats } & \multicolumn{5}{|c|}{ Nilai $\times$ Bobot } & \multirow{2}{*}{ Total } \\
\cline { 2 - 11 } & T1 & T2 & T3 & T4 & T5 & 0,4 & 0,2 & 0,2 & 0,1 & 0,1 & \\
\hline 1 & 4 & 4 & 4 & 4 & 4 & 0,8 & 0,8 & 0,8 & 0,8 & 0,8 & 4 \\
\hline 2 & 5 & 5 & 5 & 5 & 5 & 1 & 1 & 1 & 1 & 1 & 5 \\
\hline 3 & 2 & 4 & 5 & 4 & 3 & 0,4 & 0,8 & 1 & 0,8 & 0,6 & 3,6 \\
\hline 4 & 5 & 4 & 4 & 3 & 3 & 1 & 0,8 & 0,8 & 0,6 & 0,6 & 3,8 \\
\hline 5 & 3 & 3 & 3 & 5 & 4 & 0,6 & 0,6 & 0,6 & 1 & 0,8 & 3,6 \\
\hline 6 & 3 & 4 & 4 & 4 & 4 & 0,6 & 0,8 & 0,8 & 0,8 & 0,8 & 3,8 \\
\hline 7 & 4 & 3 & 4 & 4 & 4 & 0 & 0,6 & 0,8 & 0,8 & 0 & 3 \\
\hline
\end{tabular}




\section{Kuadran Matrik IFAS dan EFAS}

Dari hasil perhitungan matrik IFAS dan EFAS yang sudah didapatkan sebelumnya dengan skor IFAS sebesar 7,4 dan skor EFAS sebesar -4,8, maka tahap selanjutnya yaitu menempatkan skor tersebut di kuadran matrik IFAS dan EFAS.

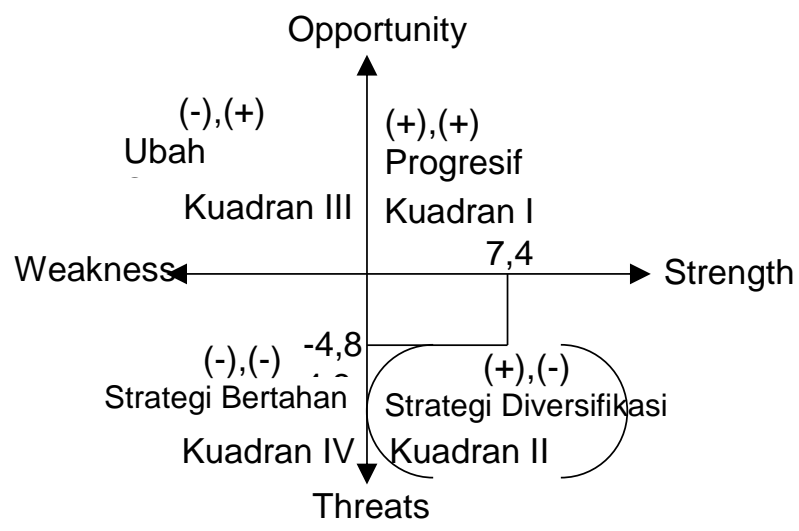

\section{Gambar 3.1. Kuadran Matrik IFAS dan EFAS}

Dari hasil perhitungan pembobotan dan penentuan posisi dikuadran matrik IFAS dan EFAS, didapatkan angka $(7,4$ dan $-4,8)$. Dimana kedua posisi ini berada pada Kuadran II dengan hasil strategi berupa "Diversifikasi". Artinya meskipun menghadapi berbagai ancaman, industri ini masih memiliki kekuatan dari sisi internal. Strategi yang harus diterapkan adalah menggunakan seluruh kekuatan yang dimiliki seperti ijin dan tempat produksi, dukungan masyarakat dan Djarum Foundation, serta ketersediaan bahan baku untuk menghadapi ancaman-ancaman yang terkait dengan pesaing, harga, dan cuaca dengan cara melakukan diversifikasi.

\section{Diamond Porter Model}

Untuk mengukur kemampuan dalam hal memperoleh keunggulan kompetitif, Klaster Industri Tomat Krispi Daumato menggambarkan industrinya melalui Diamond Porter Model. Berikut merupakan data elemen yang telah diidentifikasi dari hasil SWOT.

Chance

Munculnya produk olahan lain yang sudah menjadi branding lokal.
Firm Strategy, Structure and Rivalry

Menjaga kualitas tomat krispi

Menjaga citra (images) produk agar lebih tenar dan dikenal masyarakat terlebih di luar Malang

- Mempertahankan konsistensi anggota struktur organisasi
Demand Condition Industri olahan tomat 


\section{Gambar 3.2. Diamond Porter Model}

\section{Analisis Business Model Canvas (BMC)}

Klaster Industri Tomat Krispi Daumato mendesain model bisnisnya menggunakan Business Model Canvas untuk mengetahui konsep dasar dalam mengembangkan sebuah industri. Berikut merupakan hasil analisis BMC terhadap Klaster Industri Tomat Krispi Daumato yang telah diidentifikasi dari hasil SWOT.

\begin{tabular}{|c|c|c|c|c|}
\hline $\begin{array}{l}\text { Key Partners } \\
\text { - Dinas } \\
\text { Kesehatan } \\
\text { Pemkab } \\
\text { Malang } \\
\text { - Perguruan } \\
\text { Tinggi } \\
\text { - Djarum } \\
\text { Foundation } \\
\text { - Pemerintah } \\
\text { Desa } \\
\text { Tegalweru }\end{array}$ & $\begin{array}{l}\text { Key Activities } \\
\text { - Memproduksi } \\
\text { Daumato } \\
\text { - Pengemasan } \\
\text { tepat waktu } \\
\text { - Distribusi } \\
\text { bahan baku } \\
\text { dan produk } \\
\text { jadi } \\
\text { Key Resources } \\
\text { - Bahan baku } \\
\text { - Alat Produksi } \\
\text { - Tenaga kerja } \\
\text { (SDM) } \\
\text { - Tempat } \\
\text { produksi }\end{array}$ & $\begin{array}{l}\text { Value Proportion } \\
\text { - Akses sumber } \\
\text { daya } \\
\text { terjangkau } \\
\text { - Pelayanan } \\
\text { efisien } \\
\text { - Pendampingan }\end{array}$ & $\begin{array}{l}\text { Channels } \\
\text { - Pemasaran melalui } \\
\text { media sosial } \\
\text { - Penjualan secara } \\
\text { langsung maupun } \\
\text { online } \\
\text { - Distribusi produk } \\
\text { menggunakan kurir }\end{array}$ & $\begin{array}{l}\text { Customer } \\
\text { Segments } \\
\text { - Bapak-bapak dan } \\
\text { ibu-ibu } \\
\text { - Remaja } \\
\text { - Anak-anak }\end{array}$ \\
\hline \multicolumn{3}{|c|}{$\begin{array}{l}\text { Cost Structure } \\
\text { - Biaya tenaga kerja dan produksi } \\
\text { - Biaya tetap operasional, alat, desain dan kemasan } \\
\text { - Biaya-biaya lain seperti distribusi dan biaya tak terduga }\end{array}$} & \multicolumn{2}{|c|}{$\begin{array}{l}\text { Revenue Streams } \\
\text { - Hasil penjualan } \\
\text { - Bantuan dana pemberdayaan (Djarum } \\
\text { Foundation) }\end{array}$} \\
\hline
\end{tabular}

Gambar 3.3. Template Business Model Canvas

\section{Analisis Sembilan Elemen BMC dengan SWOT}

Setelah melakukan identifikasi terhadap SWOT dan model bisnis BMC pada Klaster Industri Tomat Krispi Daumato, selanjutnya yaitu tahap analisis 9 elemen bisnis 
BMC dengan SWOT. Dimana tujuan analisis SWOT ini untuk menganalisis faktor eksternal dan internal pada Klaster Industri Tomat Krispi Daumato.

\begin{tabular}{|c|c|c|c|c|c|}
\hline No & Unsur & Kekuatan & Kelemahan & Peluang & Ancaman \\
\hline 1. & Key Partners & $\begin{array}{l}\text { Organisasi terstruktur } \\
\text { dengan baik }\end{array}$ & $\begin{array}{c}\text { Kurang kerjasama } \\
\text { dalam mengelola } \\
\text { usaha }\end{array}$ & $\begin{array}{l}\text { Membentuk sebuah } \\
\text { koperasi agar } \\
\text { kerjasama terintegrasi } \\
\text { satu sama lain }\end{array}$ & $\begin{array}{l}\text { Konsistensi anggota } \\
\text { kurang maksimal }\end{array}$ \\
\hline 2. & Key Activities & $\begin{array}{c}\text { Proses produksi dan } \\
\text { pengemasan berjalan } \\
\text { efisien }\end{array}$ & $\begin{array}{l}\text { Pre Order konsumen } \\
\text { sering menumpuk }\end{array}$ & $\begin{array}{l}\text { Perlu dibuat sistem } \\
\text { manajemen yang bisa } \\
\text { mengatur jalannya } \\
\text { usaha ini }\end{array}$ & $\begin{array}{c}\text { Persaingan bisnis } \\
\text { dengan tengkulak } \\
\text { mendominasi } \\
\text { pemasaran }\end{array}$ \\
\hline 3. & $\begin{array}{c}\text { Key } \\
\text { Resources }\end{array}$ & $\begin{array}{c}\text { Bahan baku tersedia } \\
\text { dan tempat produksi } \\
\text { yang memadai }\end{array}$ & $\begin{array}{l}\text { Tidak memiliki } \\
\text { karyawan tetap }\end{array}$ & $\begin{array}{c}\text { Sumber daya alam } \\
\text { yang bisa } \\
\text { dimanfaatkan }\end{array}$ & $\begin{array}{c}\text { Ketersediaan alat } \\
\text { produksi sangat } \\
\text { memengaruhi }\end{array}$ \\
\hline 4. & $\begin{array}{l}\text { Value } \\
\text { Proportions }\end{array}$ & $\begin{array}{l}\text { Sudah memiliki ijin } \\
\text { produksi P-IRT dari } \\
\text { Dinas Kesehatan }\end{array}$ & $\begin{array}{l}\text { Ketersediaan bahan } \\
\text { baku utama yaitu } \\
\text { tomat yang menurun }\end{array}$ & $\begin{array}{c}\text { Memperluas } \\
\text { networking dengan } \\
\text { mitra-mitra strategis }\end{array}$ & $\begin{array}{c}\text { Terkendala waktu } \\
\text { pendampingan dengan } \\
\text { kegiatan pribadi anggota } \\
\text { beswan }\end{array}$ \\
\hline 5. & $\begin{array}{c}\text { Customer } \\
\text { Relationship }\end{array}$ & $\begin{array}{l}\text { Memiliki hubungan } \\
\text { kuat dengan } \\
\text { konsumen }\end{array}$ & $\begin{array}{c}\text { Belum menjangkau } \\
\text { pasar offline maupun } \\
\text { e-commerce }\end{array}$ & $\begin{array}{c}\text { Penjualan online dan } \\
\text { mendirikan stand di } \\
\text { Car Free Day }\end{array}$ & $\begin{array}{c}\text { Memberikan penawaran } \\
\text { yang lebih menarik dari } \\
\text { pesaing lainnya }\end{array}$ \\
\hline 6. & Channels & $\begin{array}{c}\text { Memiliki laman khusus } \\
\text { dan media sosial } \\
\text { (instagram) untuk } \\
\text { promosi }\end{array}$ & $\begin{array}{c}\text { Kurangnya koordinasi } \\
\text { antar pelaku usaha } \\
\text { dan distribusi sering } \\
\text { terhambat } \\
\end{array}$ & $\begin{array}{l}\text { Perluasan distribusi } \\
\text { melalui e-commerce }\end{array}$ & $\begin{array}{c}\text { Banyaknya pesaing } \\
\text { yang berlomba-lomba } \\
\text { mencari keutungan lebih } \\
\text { banyak }\end{array}$ \\
\hline 7. & $\begin{array}{l}\text { Customer } \\
\text { Segments }\end{array}$ & $\begin{array}{l}\text { Konsumen tomat } \\
\text { krispi Daumato dari } \\
\text { berbagai usia }\end{array}$ & $\begin{array}{c}\text { Daumato belum } \\
\text { dikenal banyak } \\
\text { masyarakat }\end{array}$ & $\begin{array}{c}\text { Pelaku pasar terbuka } \\
\text { lebar }\end{array}$ & $\begin{array}{l}\text { Pesaing yang terus } \\
\text { mengeluarkan produk } \\
\text { sejenis (keripik) }\end{array}$ \\
\hline 8. & Cost Structure & $\begin{array}{l}\text { Biaya operasional } \\
\text { efisien dan biaya lain } \\
\text { dapat diprediksi }\end{array}$ & $\begin{array}{l}\text { Sistem penggajian } \\
\text { yang tidak terstruktur }\end{array}$ & $\begin{array}{c}\text { Meningkatkan } \\
\text { teknologi perkebunan } \\
\text { dan pengolahan } \\
\text { Daumato } \\
\end{array}$ & $\begin{array}{l}\text { Harga bahan baku yang } \\
\text { fluktuatif }\end{array}$ \\
\hline 9. & $\begin{array}{l}\text { Revenue } \\
\text { Streams }\end{array}$ & $\begin{array}{l}\text { Penjualan langsung, } \\
\text { penjualan daring } \\
\text { (online) dan dana } \\
\text { pemberdayaan dari } \\
\text { Djarum Foundation }\end{array}$ & $\begin{array}{l}\text { Pemasaran yang } \\
\text { belum berkembang } \\
\text { menyebabkan } \\
\text { pendapatan fluktuatif }\end{array}$ & $\begin{array}{l}\text { Mengembangkan } \\
\text { sistem pemasaran }\end{array}$ & $\begin{array}{l}\text { Minat beli masyarakat } \\
\text { menurun }\end{array}$ \\
\hline
\end{tabular}

\section{Analisis Strategi Pengembangan Model Bisnis}

Strategi pengembangan model bisnis Klaster Industri Tomat Krispi Daumato dirumuskan berdasarkan hasil analisis Diamond Porter Model, pemetaan model bisnis klaster dan analisis 9 elemen Business Model Canvas terhadap SWOT. Berikut merupakan perumusan strategi pengembangan Klaster Industri Tomat Krispi Daumato yang dihasilkan melalui matrik SWOT.

Tabel 3.4. Matrik Interaksi SWOT 


\begin{tabular}{|c|c|c|}
\hline External & $\begin{array}{l}\text { 1. Organisasi terstruktur dengan baik } \\
\text { 2. Proses produksi dan pengemasan } \\
\text { berjalan efisien } \\
\text { 3. Bahan baku tersedia dan tempat } \\
\text { produksi yang memadai } \\
\text { 4. Sudah memiliki ijin produksi P-IRT dari } \\
\text { Dinas Kesehatan } \\
\text { 5. Memiliki hubungan kuat dengan } \\
\text { konsumen } \\
\text { 6. Memiliki laman khusus dan media } \\
\text { 7osial (instagram) untuk promosi } \\
\text { 7. Konsumen tomat krispi Daumato dari } \\
\text { berbagai usia } \\
\text { 8. Biaya operasional efisien dan biaya lain } \\
\text { dapat diprediksi } \\
\text { 9. Penjualan langsung, penjualan online } \\
\text { dan dana pemberdayaan dari Djarum } \\
\text { Foundation }\end{array}$ & $\begin{array}{l}\text { 1. Kurang kerjasama dalam mengelola } \\
\text { usaha } \\
\text { 2. Pre Order konsumen sering } \\
\text { menumpuk } \\
\text { 3. Tidak memiliki karyawan tetap } \\
\text { 4. Ketersediaan bahan baku utama } \\
\text { yaitu tomat yang menurun } \\
\text { 5. Belum menjangkau pasar offline } \\
\text { maupun e-commerce } \\
\text { 6. Kurangnya koordinasi antar pelaku } \\
\text { usaha dan distribusi sering terhambat } \\
\text { 7. Daumato belum dikenal banyak } \\
\text { masyarakat } \\
\text { 8. Sistem penggajian yang tidak } \\
\text { terstruktur } \\
\text { 9. Pemasaran yang belum berkembang } \\
\text { menyebabkan pendapatan fluktuatif }\end{array}$ \\
\hline $\begin{array}{l}\text { OPPORTUNITY: } \\
\text { 1. Membentuk sebuah koperasi agar } \\
\text { kerjasama terintegrasi satu sama } \\
\text { lain } \\
\text { 2. Perlu dibuat sistem manajemen } \\
\text { yang bisa mengatur jalannya usaha } \\
\text { ini } \\
\text { 3. Sumber daya alam yang bisa } \\
\text { dimanfaatkan } \\
\text { 4. Memperluas networking dengan } \\
\text { mitra-mitra strategis } \\
\text { 5. Penjualan online dan mendirikan } \\
\text { stand di Car Free Day } \\
\text { 6. Perluasan distribusi melalui } e- \\
\text { 7. Pemmerce } \\
\text { 8. Menuingkatkan terbuka lebar } \\
\text { perkebunan dan pengolahan } \\
\text { Daumato } \\
\text { 9. Mengembangkan sistem } \\
\text { pemasaran }\end{array}$ & $\begin{array}{ll}\text { S-O STRATEGY } \\
\text { 1. } \\
\begin{array}{l}\text { (S1,O1;O2) Mempertahankan } \\
\text { organisasi agar dapat membentuk } \\
\text { koperasi dan membuat sistem } \\
\text { manajemen usaha yang baik. } \\
\text { 2. }\end{array} \\
\begin{array}{l}\text { (S2,S3;O3,O8) Mempertahankan } \\
\text { kualitas sumber daya agar proses } \\
\text { produksi berjalan lancar. }\end{array} \\
\text { 3. } \quad \begin{array}{l}\text { (S4;O4) Mengembangkan potensi } \\
\text { usaha dengan mitra-mitra strategis } \\
\text { 4. }\end{array} \text { (S5,S6,S7;O5,O6,O7) Meningkatkan } \\
\text { sistem pemasaran online maupun } \\
\text { offline } \\
\text { (S8,S9;O9) Mempertahankan potensi } \\
\text { pemasaran Daumato }\end{array}$ & \begin{tabular}{ll} 
& \multicolumn{1}{c}{ W-O STRATEGY } \\
1. & (W1;O1) Meningkatkan kerjasama \\
dalam mengelola usaha \\
2. $(\mathrm{W} 2, \mathrm{~W} 3, \mathrm{~W} 8 ; \mathrm{O} 2)$ Membuat sistem \\
manajemen yang terstruktur dan \\
merekrut karyawan tetap \\
3. (W4;O3;O8) Meningkatkan teknologi \\
pengolahan perkebunan tomat \\
4. (W6;O6) Meningkatkan manajemen \\
distribusi Daumato \\
5. (W5,W7,W9;O4,O5,O7,O9) \\
Memperluas sistem pemasaran dan \\
jaringan dengan mitra-mitra strategis
\end{tabular} \\
\hline $\begin{array}{l}\text { THREATS : } \\
\text { 1. Konsistensi anggota kurang } \\
\text { maksimal } \\
\text { 2. Persaingan bisnis dengan } \\
\text { tengkulak mendominasi pemasaran } \\
\text { 3. Ketersediaan alat produksi sangat } \\
\text { mempengaruhi } \\
\text { 4. Terkendala waktu pendampingan } \\
\text { dengan kegiatan pribadi anggota } \\
\text { beswan } \\
\text { 5. Memberikan penawaran yang lebih } \\
\text { menarik dari pesaing lainnya } \\
\text { 6. Banyaknya pesaing yang } \\
\text { berlomba-lomba mencari } \\
\text { keutungan lebih banyak } \\
\text { 7. Pesaing yang terus mengeluarkan } \\
\text { produk sejenis (keripik) } \\
\text { 8. Harga bahan baku yang fluktuatif } \\
\text { 9. Minat beli masyarakat menurun }\end{array}$ & \begin{tabular}{ll}
\multicolumn{1}{c}{ S-T STRATEGY } \\
1. (S1;T1,T4) Membentuk koperasi untuk \\
meningkatkan konsistensi anggota \\
2. (S2,S3;T2,T3) Mempertahankan \\
kualitas dan harga bahan baku juga \\
menjaga alat produksi agar tetap baik \\
saat digunakan \\
3. (S4,S6;T6,T7) Meningkatkan sistem \\
pemasaran dan inovasi produk untuk \\
melawan pesaing \\
4. (S5,S7;T5) Mempertahankan hubungan \\
dengan konsumen Daumato \\
5. (S8,S9;T8,T9) Meningkatkan penjualan \\
untuk menanggulangi biaya yang \\
fluktuatif
\end{tabular} & 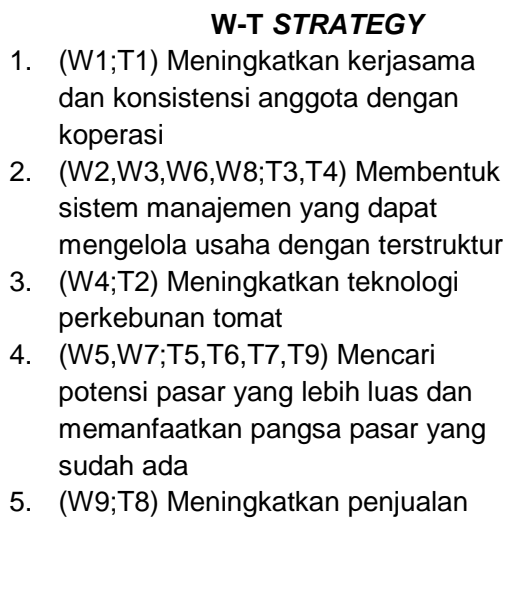 \\
\hline
\end{tabular}

\section{Pembahasan Strategi Pengembangan}

Hasil interaksi matriks SWOT selanjutnya dirumuskan dengan memperoleh empat strategi pengembangan yang kemudian dianalisis seperti dibawah ini. 
1. S-O Strategy

Dalam pengembangan usaha pada S-O Strategy, memerlukan hal berikut :

a. Membentuk sebuah koperasi untuk menjalin kerjasama antar anggota dengan baik dan membuat sistem manajemen yang terstruktur untuk mengelola usaha.

b. Mempertahankan kualitas sumber daya alam yaitu tomat agar proses produksi terus berjalan tanpa hambatan untuk memenuhi permintaan konsumen.

c. Mengembangkan potensi usaha dengan menjalin jaringan dengan mitra-mitra strategis guna meningkatkan penjualan dan keuntungan.

d. Meningkatkan sistem pemasaran melalui online maupun offline dengan menjual produk dilaman website, media sosial maupun mendirikan stand secara offline.

e. Mempertahankan potensi pasar Daumato dengan cara tetap menjaga komunikasi kepada konsumen dan mempertahankan kualitas produk Daumato.

2. W-O Strategy

Dalam pengembangan usaha pada W-O Strategy, memerlukan hal berikut :

a. Meningkatkan kerjasama dengan anggota lain untuk mengelola usaha Klaster Industri Tomat Krispi Daumato.

b. Merekrut karyawan tetap agar proses produksi berjalan sesuai jadwal dan bisa memenuhi permintaan konsumen.

c. Meningkatkan teknologi pada pengolahan perkebunan tomat agar kualitas bahan baku tomat tetap terjaga dan menjamin kualitas produk Daumato juga.

d. Meningkatkan manajemen distribusi agar pemesanan untuk konsumen bisa diantar sesuai jadwal pengiriman dan tidak terjadi penumpukan di tempat produksi.

e. Memperluas sistem pemasaran dengan menjalin jaringan mitra-mitra strategis guna meningkatkan penjualan dan keuntungan

3. S-T Strategy

Dalam pengembangan usaha pada S-T Strategy, memerlukan hal berikut :

a. Membentuk koperasi untuk meningkatkan kerjasama dan konsistensi anggota agar usaha tetap berjalan lancar.

b. Mempertahankan kualitas bahan baku dengan harga yang sesuai dan menjaga alat produksi tetap baik agar tidak menambah pengeluaran dari usaha Daumato.

c. Meningkatkan sistem pemasaran dengan cara memunculkan inovasi produk yang lebih guna menarik perhatian konsumen untuk membeli Daumato.

d. Mempertahankan hubungan baik kepada konsumen dengan membuka peluang menjadi supplier Daumato.

e. Meningkatkan penjualan Daumato untuk mengantisipasi adanya bahan dengan harga yang fluktuatif.

4. W-T Strategy

Dalam pengembangan usaha pada W-T Strategy, memerlukan hal berikut :

a. Meningkatkan kerjasama dan konsistensi anggota dengan membentuk sebuah koperasi.

b. Membentuk sistem manajemen yang terstruktur agar dapat mengelola Klaster Industri Tomat Krispi Daumato.

c. Meningkatkan teknologi perkebunan tomat dengan menjaga kualitas tomat dan menjaga pertumbuhan tomat dengan baik untuk produksi.

d. Mencari potensi pangsa pasar yang lebih luas dan mempertahankan konsumen yang sudah menjadi pelanggan tetap pada produk Daumato.

e. Meningkatkan penjualan dengan membuka peluang konsumen untuk menjadi supplier Daumato.

\section{Kesimpulan}

Berdasarkan hasil dari pengolahan data dan analisis, maka dapat disimpulkan bahwa : 
1. Strategi yang harus diterapkan berdasarkan hasil matrik IFAS dan EFAS dalam analisis SWOT adalah menggunakan kekuatan yang dimiliki baik secara internal maupun eksternal untuk menghadapi ancaman-ancaman yang terkait dengan pesaing, harga, ketersediaan bahan baku dengan cara melakukan diversifikasi.

2. Strategi Pengembangan berdasarkan identifikasi Diamond Porter Model dan pemetaan 9 elemen bisnis model BMC yang dilanjutkan analisis matrik interaksi SWOT menghasilkan: S-O, W-O, S-T, dan W-T Strategy dan disimpulkan dalam 5 (lima) strategi pengembangan yakni :

1. Membentuk sebuah koperasi untuk menjalin kerjasama antaranggota dengan baik, termasuk membuat sistem manajemen yang terstruktur

2. Mempertahankan kualitas tomat dan merekrut karyawan tetap agar proses produksi berjalan sesuai jadwal dan bisa memenuhi permintaan konsumen.

3. Mengembangkan potensi usaha dengan menjalin jaringan dengan mitra-mitra strategis guna meningkatkan penjualan dan keuntungan.

4. Mempertahankan hubungan baik kepada konsumen dengan membuka peluang menjadi supplier (pemasok).

5. Meningkatkan penjualan produk untuk mengantisipasi adanya bahan dengan harga yang fluktuatif.

\section{Daftar Pustaka}

[1] Ety Saraswati, Aleria Irma Hatneny, Andi Normala Dewi. (2019). Implementasi Model Diamond Porter dalam Membangun Keunggulan Bersaing pada Kawasan Agrowisata Kebun Belimbing Ngringinrejo Bojonegoro. Jurnal IImu Manajemen Volume 4 Nomor 2. Pp $108-132$

[2] Bambang Supriadi (2018) Pengembangan Ekowisata Poncokusumo melalui Grand Strategy Matrix Analysis. Jurnal Pariwisata Pesona Volume 3 Nomor 2 pp 119 - 133

[3] Lumsari, Uyu. (2007). Strategi Pengembangan Klaster Industri Genteng Dengan Menggunakan Analisis SWOT (Studi Kasus : Perusahaan Genteng Di Karanggeneng Boyolali),

[4] Osterwalder, Alexander dan Pigneur,Yves. Edisi Terjemahan (2017). Business Model Generation. Jakarta. Penerbit Gramedia.

[5] Papilo, Petir dan Bantacut, Tajuddin. (2016). Klaster Industri Sebagai Strategi Peningkatan Daya Saing Agroindustri Bioenergi Berbasis Kelapa Sawit, Jurnal Teknik Industri, Vol XI, No 2, Pp: 90-91

[6] Pusat Data dan Statistik Pendidikan. Kementrian Pendidikan dan Kebudayaan Republik Indonesia, (2014). Modul Pembelajaran SPSS

[7] Rizkita, Nyanyu dkk. (2018). Strategi Pengembangan Model Bisnis Klaster Industri Produk Olahan Susu Cipageran, Jurnal MPI, Volume 13 Nomor 1 Pp $75-86$

[8] Susanto, Budi. (2007). Analisis Sistem Evaluasi Klaster Industri (Studi Kasus pada Industri Alat Angkut Mesin dan Peralatannya di Propinsi Jabar), Berita Teknologi Bahan dan Barang Teknik No.21/2007.

[9] Sylvia Saragi Sitio, Vera. (2017). Strategi Bisnis Model Dengan Pendekatan Business Model Canvas (Studi Kasus di Industri Kecil dan Menengah (IKM) Bir Pletok Bu Lina Kelurahan Ciracas, Jakarta Timur), Journal of Economics and Business Aseanomics Volume 2 Nomor 1 Pp $36-51$ 